\title{
Produção e composição do efluente da silagem de capim-elefante com casca de café
}

\section{Dawson José Guimarães Faria ${ }^{1}$, Rasmo Garcia ${ }^{2}$, Rafael Gonçalves Tonucci ${ }^{3}$, Valdir Botega Tavares $^{4}$, Odilon Gomes Pereira ${ }^{2}$, Dilermando Miranda da Fonseca ${ }^{2}$}

1 Instituto Federal Minas Gerais - campus Bambuí.

2 Departamento de Zootecnia - UFV. Bolsista do CNPq.

${ }^{3}$ Doutorando em Zootecnia - UFV

${ }^{4}$ Departamento de Zootecnia - UFLA.

RESUMO - O experimento foi conduzido para avaliar os efeitos do processamento (com ou sem moagem) e da inclusão de casca de café na silagem de capim-elefante sobre a produção e composição do efluente. Utilizou-se um delineamento inteiramente casualizado em esquema fatorial $2 \times 5$, com dois processamentos (com ou sem moagem) e cinco níveis de casca (0; 6; 12; 18 e 24\%), cada um com três repetições. Para avaliação da composição do efluente, adotou-se o esquema de parcelas subdivididas, em que a parcela principal foi constituída de fatorial $2 \times 3$, com dois processamentos e três níveis de casca (0; 6; 12\%) e a subparcela, dos dias de colheita do efluente, com três repetições. A produção total de efluente foi de 243,1 L/t de silagem para a silagem sem casca, de 196,8; 93,2; 30,8; 3,1 L/t e de 149,1; 52,3; 30,8 e 0,0 L/t para as silagens com a casca inteira e moída nos níveis de 6, 12, 18 e 24\%, respectivamente. O processamento da casca e os níveis de inclusão tiveram efeito quadrático, no tempo, sobre os teores de sólidos totais e nitrogênio total. Foi detectado efeito quadrático do processamento e dos dias e dos níveis de casca e dias, respectivamente, sobre a composição em cálcio e magnésio. Os níveis de casca e o processamento da casca de café tiveram efeito linear sobre o conteúdo de fósforo no efluente. Houve efeito do processamento, dos níveis de casca e dos dias nas demandas química e bioquímica de oxigênio. A casca de café é eficiente em reduzir a produção de efluente da silagem de capim-elefante, principalmente quando moída, pois tem mais efeito que inteira. A composição do efluente é influenciada pelos dias de coleta do efluente e pelos níveis e processamento da casca de café.

Palavras-chave: aditivo absorvente, ensilagem, perdas, poluição ambiental, processamento

\section{Production and composition of elephant grass and coffee hull silage effluent}

\begin{abstract}
The experiment was carried out to evaluate the effects of processing (whole or ground) and including coffee hulls in elephant grass silage on the effluent production and composition. A randomized complete design in a $2 \times 5$ factorial design with two processes (whole or ground) and five coffee hull levels (0; 6; $12 ; 18$ and $24 \%$ ) each with three replications. A split-plot design was used to assess the effluent composition, where the main plot consisted of a $2 \times 3$ factorial with two processes and three coffee hull levels $(0,6,12 \%)$ and the split-plot consisted of the effluent collection days, with three replications. The total effluent production was $243.1 \mathrm{~L} / \mathrm{t}$ silage for silage without hulls, 196.8; 93.2; 30.8; 3.1 and 149.1; 52.3; 30.8; $0.0 \mathrm{~L} / \mathrm{t}$ for the silages with whole and ground hulls at levels of 6, 12, 18 and 24\%, respectively. The hull processing and inclusion levels had a quadratic effect, according to the days, on the total solids and total nitrogen contents. A quadratic effect of the processing and days and the hull levels and days, respectively, on the composition in calcium and magnesium. The hull levels and the coffee hull processing had a linear effect on the phosphorus content in the effluent. There were effects of processing, hull levels and of the days on the contents of chemical and biochemical demands for oxygen. Coffee hulls were efficient in reducing effluent production in the elephantgrass silage, especially when ground, because they had more effect than when whole. The effluent composition is influenced by the day of collection and inclusion and processing of coffee hull levels.
\end{abstract}

Key Words: absorbent additive, ensilage, environmental pollution, losses, processing

\section{Introdução}

A estacionalidade de produção das forrageiras faz com que a exploração pecuária com base no alto potencial de produção das gramíneas tropicais exija a utilização de estratégias que permitam atender a exigência animal durante todo o ano.

A silagem é uma alternativa para atender a falta de volumosos no período da seca. O capim-elefante é estudado

Recebido em 11/8/2008 e aprovado em 19/2/2009.

Correspondências devem ser enviadas para: dawsonfaria@bol.com.br 
há muitas décadas, mas os produtores e técnicos ainda vêem a necessidade de se obter uma silagem melhor desta forrageira, visto que seu elevado teor de umidade conduz a perdas na ensilagem. As perdas por efluente reduzem o valor nutricional da silagem, pois na solução existem nutrientes, como carboidratos solúveis, ácidos orgânicos, minerais e compostos nitrogenados solúveis, o que leva a maior proporção dos componentes da parede celular na silagem, que são nutricionalmente menos desejáveis.

Quando o efluente é escoado para cursos d'água, as substâncias nele contidas são utilizadas por microrganismos e, durante o processo, parte ou todo o oxigênio presente na água pode esgotar-se. A demanda bioquímica de oxigênio do efluente da silagem é muito maior que a do esgoto doméstico, tornando-se um sério poluente para os lençóis freáticos (Loures et al., 2003).

Segundo Nússio et al. (2002), as perdas por efluente podem ser evitadas utilizando forragens naturalmente secas, misturando culturas mais secas às mais úmidas na ensilagem. Pereira \& Bernardino (2004) também relataram que o uso de aditivos absorventes ou o emurchecimento da cultura tem sido a técnica mais recomendada para o controle da produção de efluentes em silagens.

Por sua disponibilidade nas regiões produtoras de café, a casca de café tem sido pesquisada e usada como aditivo absorvente, pois tem elevado teor de matéria seca e boa capacidade de retenção de umidade. Além disso, pode ser utilizada na dieta de ruminantes e seu uso está se tornando comum entre os pecuaristas.

A capacidade de retenção do aditivo absorvente varia com o tipo de material utilizado: materiais mais fibrosos, como sabugo de milho, polpa de beterraba ou palhadas, apresentam maior retenção que outros materiais, como grãos de cereais (Jones \& Jones, 1996). Outra característica que afeta a capacidade de retenção do aditivo é o grau de moagem, pois materiais finamente moídos retêm mais umidade em comparação a outros não moídos ou moídos grosseiramente.

Objetivou-se avaliar a produção e a composição do efluente da silagem de capim-elefante adicionada de casca de café.

\section{Material e Métodos}

O experimento foi conduzido no Departamento de Zootecnia da Universidade Federal de Viçosa (UFV), Viçosa, Minas Gerais, no período de 27/01/2004 a 27/04/2004. As análises laboratoriais foram realizadas nos Laboratórios de Forragicultura e de Nutrição Animal do Departamento de Zootecnia e no Laboratório de Matéria Orgânica e Resíduos do Departamento de Solos da Universidade Federal de Viçosa. A espécie forrageira utilizada foi o capim-elefante (Pennisetum purpureum Schum), cultivar Cameroon, oriundo de uma capineira já estabelecida no Departamento de Zootecnia da UFV. Esta capineira está situada em área de baixada e recebe anualmente adubação com esterco de curral.

O capim-elefante foi cortado manualmente no dia 27 de janeiro de 2004, picado em partículas de 2 a $5 \mathrm{~cm}$ de comprimento, utilizando-se máquina forrageira acoplada ao trator, e ensilado no mesmo dia. No momento do corte, o capim-elefante estava com aproximadamente 70 dias de idade (rebrota) e 1,80 m de altura.

A casca de café utilizada foi adquirida em Viçosa e parte foi triturada em moinho tipo martelo com peneira de $3 \mathrm{~mm}$ e adicionada, inteira ou moída, ao capim recémpicado nos níveis de $0,6,12,18$ e 24\%, com base na matéria natural $(0,60,120,180$ ou $240 \mathrm{~kg}$ de casca de café por tonelada de capim verde), e misturada até homogeneização. Procedeu-se em seguida à ensilagem, em silos laboratoriais dePVC com 0,25 m de diâmetroe 0,75 m de altura, colocando-se em cada silo $10 \mathrm{~kg}$ da mistura de capim e casca de café e efetuando-se compactação da massa ensilada com auxílio de soquetes, até a altura de $0,37 \mathrm{~m}$, obtendo-se densidade de $550 \mathrm{~kg} / \mathrm{m}^{3}$. Após o enchimento, os silos foram vedados com tampa de madeira revestida por plástico e cobertos com sacos plásticos para evitar a entrada de água e oxigênio. No momento da ensilagem, retiraram-se amostras do capimelefante e da casca de café (Tabela 1), que foram armazenadas em freezer para posteriores análises.

Tabela 1 - Composição nutricional do capim-elefante e da casca de café utilizados na produção das silagens

\begin{tabular}{lrr}
\hline Item & Capim-elefante & Casca de café \\
\hline Matéria seca & 12,72 & 81,20 \\
Proteína bruta (\% MS) & 11,79 & 8,16 \\
Fibra em detergente neutro (\% MS) & 66,67 & 62,20 \\
Fibra em detergente ácido (\% MS) & 47,17 & 50,35 \\
NIDN (\% NT) & 24,69 & 37,12 \\
NIDA (\% NT) & 5,34 & 23,62 \\
Lignina (\% MS) & 11,32 & 16,86 \\
Celulose (\% MS) & 35,85 & 35,91 \\
Hemicelulose (\% MS) & 19,50 & 11,85 \\
Extrato etéreo (\% MS) & 1,24 & 0,97 \\
Cinza (\% MS) & 12,05 & 5,78 \\
Cálcio (\% MS) & 0,38 & 0,29 \\
Fósforo (\% MS) & 0,28 & 0,13 \\
Sódio (\% MS) & 0,02 & 0,01 \\
Potássio (\% MS) & 3,92 & 2,17 \\
Magnésio (\% MS) & 0,21 & 0,07 \\
DIVMS (\% MS) & 68,23 & 50,79 \\
\hline
\end{tabular}

NIDN = nitrogênio insolúvel em detergente neutro; NIDA = nitrogênio insolúvel em detergente ácido; DIVMS = digestibilidade in vitro da matéria seca. 
Até a abertura dos silos, realizada 90 dias após o fechamento, efetuou-se a colheita do efluente mediante tubulação com registro de rosca, existente na parte inferior dos silos. O efluente foi colhido diariamente até 28 dias após o fechamento do silo: duas vezes até o 12 o dia e uma vez até o 28ํㅡㅁ dia. Após este período, a colheita foi realizada a cada três dias, devido ao pequeno volume de efluente produzido.

O volume total de efluente de cada silo experimental foi medido com o auxílio de uma proveta e logo após, as amostras de 50 a $60 \mathrm{~mL}$ de efluente foram armazenadas em frascos plásticos com tampas e colocadas em freezer para posterior análise. Foram determinadas as demandas bioquímica e química de oxigênio, segundo Silva (1977), bem como os teores de minerais ( $\mathrm{Ca}, \mathrm{P}, \mathrm{Mg}$ e $\mathrm{K}$ ) e nitrogênio total (NT), conforme descrito por Silva \& Queiroz (2002). Os sólidos totais ou a matéria seca do efluente foram determinados por meio de secagem em estufas de 65 e $105^{\circ} \mathrm{C}$.

Nas análises, foram utilizadas somente as amostras de efluente dos primeiros sete dias de colheita e das silagens com 0, 6 e 12\% de casca de café, uma vez que as demais amostras não tinham quantidades suficientes para análises e pelo fato que a primeira semana de colheita do efluente responder por mais de $50 \%$ da produção total de efluente.

Para a avaliação da produção de efluente, utilizou-se esquema fatorial $2 \times 5$, com dois processamentos da casca de café (com ou sem moagem) e cinco níveis de casca de café (0; 6; 12; 18 e 24\% da matéria natural), dispostos em um delineamento inteiramente casualizado, com três repetições. Para o estudo da composição do efluente, utilizou-se delineamento experimental inteiramente casualizado e adotou-se esquema de parcela subdivididas, de modo que a parcela principal foi constituída de um fatorial $2 \times 3$, com dois processamentos da casca (com ou sem moagem) e três níveis de casca $(0 ; 6 ; 12 \%)$. A subparcela foi constituída dos dias de colheita do efluente, com três repetições. Os dados foram analisados por meio de análise de variância e regressão. Para o efeito do processamento foi utilizada a variável Dummy, atribuindo-se para o efeito do processamento na equação de regressão valor 0 , se a observação fosse referente à casca inteira (sem processamento), ou valor 1 , se a observação fosse referente à casca moída (com processamento).

As análises estatísticas foram realizadas utilizando-se o programa SAEG (Sistema de Análise Estatística e Genética), desenvolvido pela Universidade Federal de Viçosa (1997).

\section{Resultados e Discussão}

$\mathrm{Na}$ primeira semana, apenas as silagens sem casca de café e aquelas com 6 e 12\% de casca inteira e moída e 18\% de casca inteira produziram efluente (Figura 1). O pico de produção foi registrado no primeiro dia de colheita, quando provavelmente a disponibilidade de oxigênio já havia se esgotado, o que, segundo Woolford (1984), contribui para ruptura da membrana celular da planta, facilitando a perda de conteúdos celulares.

Da produção total de efluente das silagens com $0 \%$ de casca, $6 \%$ de casca inteira, $6 \%$ de casca moída, 12\% de casca inteira, $12 \%$ de casca moída e $18 \%$ de casca inteira, respectivamente, 68,5; 55,7; 59,7; 44,0; 52,4 e 36,8\% foram produzidos na primeira semana. Bernardes et al. (2003) observaram que mais de 80,75 e $30 \%$ do total do efluente foram produzidos no primeiro dia de ensilagem para as silagens de capim-marandu com 0, 5 e 10\% de polpa cítrica peletizada, respectivamente, e que, após o quinto dia de colheita, não foi observada produção de efluente. Loures et al. (2003) relataram em pesquisa com capim-elefante que mais de 55\% do total do efluente foi produzido nos dois primeiros dias em todas as compactações utilizadas (356,67; 446,67; 531,33; 684,00; 791,00 kg/m³) na ensilagem de capim-elefante com $13 \%$ de MS.

A produção total de efluente teve efeito $(\mathrm{P}<0,05)$ dos níveis de casca de café e do processamento (Figura 1). Para a produção total de efluente, escolheu-se o modelo que
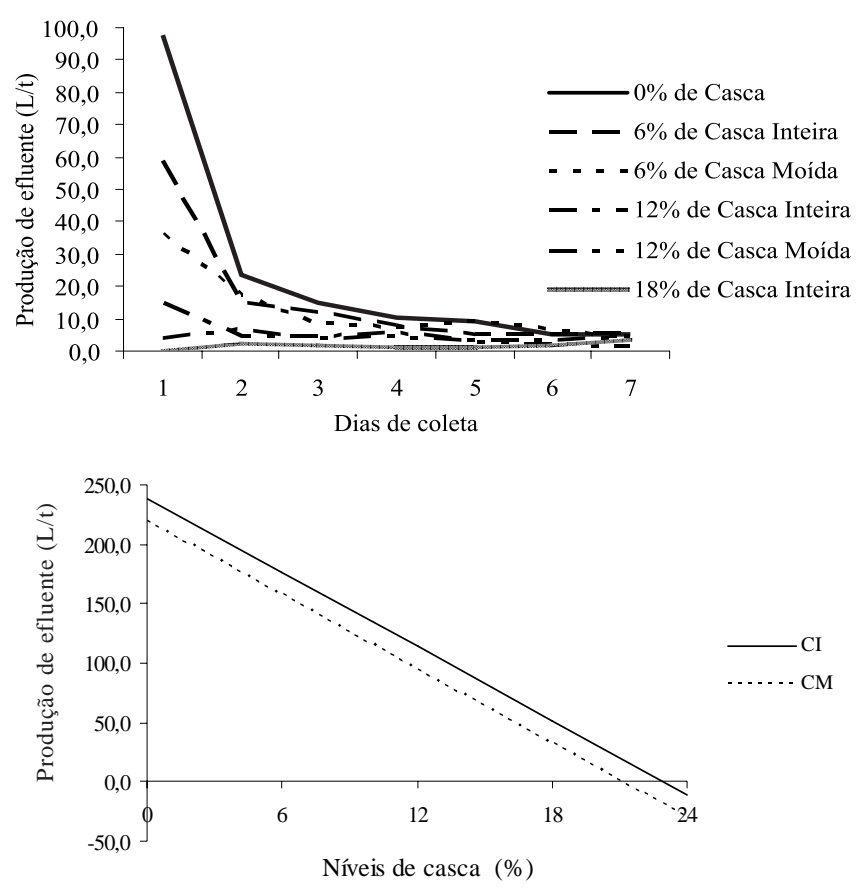

$\hat{\mathrm{Y}}=238,73-10,4136 * \mathrm{CA}-19,0067 * \mathrm{PR} ; \mathrm{R}^{2}=0,9430$

* Significativo a $5 \%$ de probabilidade pelo teste "t”.

Figura 1 - Produção observada de efluente (L/t) em função dos dias de colheita (a) e produção estimada de efluente (b) da silagem de capim-elefante com doses de inclusão de casca de café inteira (CI) e moída (CM). 
melhor explicou $\left(\mathrm{R}^{2}=0,943\right)$ a variação dos dados, mesmo que a produção estimada para a inclusão de $24 \%$ de casca de café, tanto inteira como moída, tenha sido negativa e não possa ser biologicamente explicada. A inclusão de casca de café nas silagens reduziu a produção de efluente, uma vez que as silagens com $18 \%$ e $24 \%$ de casca praticamente não produziram efluente (Tabela 2). Esse fato esteve relacionado à elevada quantidade de matéria seca da casca de café e sua boa capacidade de retenção de água e comprova a eficiência deste material como aditivo absorvente. Quando a casca de café é incluída no nível de 18\% ou superior, não é necessário o processamento, mas esses níveis podem comprometer as características quimico-bromatológicas da silagem.

Bernardino et al. (2005) observaram que apenas as silagens de capim-elefante sem casca de café e com 10\% deste aditivo produziram efluentes, com volumes totais de 123,5 e 26,7 L/t de silagem. Bernardes et al. (2003) relataram que a inclusão de 5 e 10\% de polpa cítrica reduziu em 35 e 85\% da produção total de efluente em comparação à silagem controle. Neste experimento, o volume final de efluente obtido com a casca moída foi menor que o da casca inteira em todos os níveis (Figura 2). Esses resultados são semelhantes aos encontrados por Dexter (1961), citado por Jones \& Jones (1996), que comparou a capacidade de reter água de diversos aditivos absorventes e notou que o grau de moagem era importante, pois materiais finamente moídos retinham mais água que quando moídos de forma mais grosseira.

Os níveis de casca de café, os dias de colheita e a interação dose de inclusão $\times$ processamento tiveram efeito quadrático $(\mathrm{P}<0,05)$ sobre as porcentagens de sólidos totais do efluente (Figura 2). A concentração de sólidos totais aumentou com a inclusão de casca de café, fato que pode ser explicado pelo efeito de concentração, já que as silagens com $12 \%$ de casca de café produziram menor quantidade de efluente. Bernardes et al. (2003) também observaram aumento nos teores de MS do efluente com a inclusão de polpa cítrica na silagem de capim-marandu; os valores médios foram de 3,8; 5,0 e 7,5\% de MS, respectivamente, para os níveis de 0; 5 e 10\%. Esses autores também notaram interação adição de polpa $\times$ tempo de ensilagem com o aumento nos valores de

Tabela 2 - Produções totais de efluente observadas (L/t) da silagem de capim-elefante contendo casca de café inteira ou moída

\begin{tabular}{lccccc}
\hline Casca de café & \multicolumn{5}{c}{ Casca de café $(\% \mathrm{MN})$} \\
\cline { 2 - 6 } & 0 & 6 & 12 & 18 & 24 \\
\hline Inteira & 244,8 & 196,8 & 93,2 & 30,8 & 3,1 \\
Moída & 241,3 & 149,1 & 52,3 & 30,8 & 0,0 \\
\hline
\end{tabular}

MS durante os cinco dias de colheita de efluente. Haigh (1999) encontrou valores médios de MS (matéria seca) de 67000 mG/L para silagens de gramíneas de clima temperado tratadas com aditivos. Segundo esse autor, os aditivos têm pequeno efeito no teor de MS do efluente, com exceção dos aditivos absorventes, que podem aumentar os teores de MS. O efeito do processamento pode ser explicado pelo fato de que as partículas com menor tamanho são arrastadas com maior facilidade pelo efluente. Neste experimento, os valores mínimos estimados ocorreram no quinto $(4,8)$ dia, com valores de 2,15; 3,15; 4,90 para os níveis de 0 , 6 e $12 \%$ de casca inteira e de 2,15; 3,58 e 5,76\% para os níveis de 0,6 e 12\% de casca moída. Loures et al. (2003) também verificaram efeito quadrático dos dias de colheita sobre os teores de sólidos totais do efluente da silagem de capim-elefante com
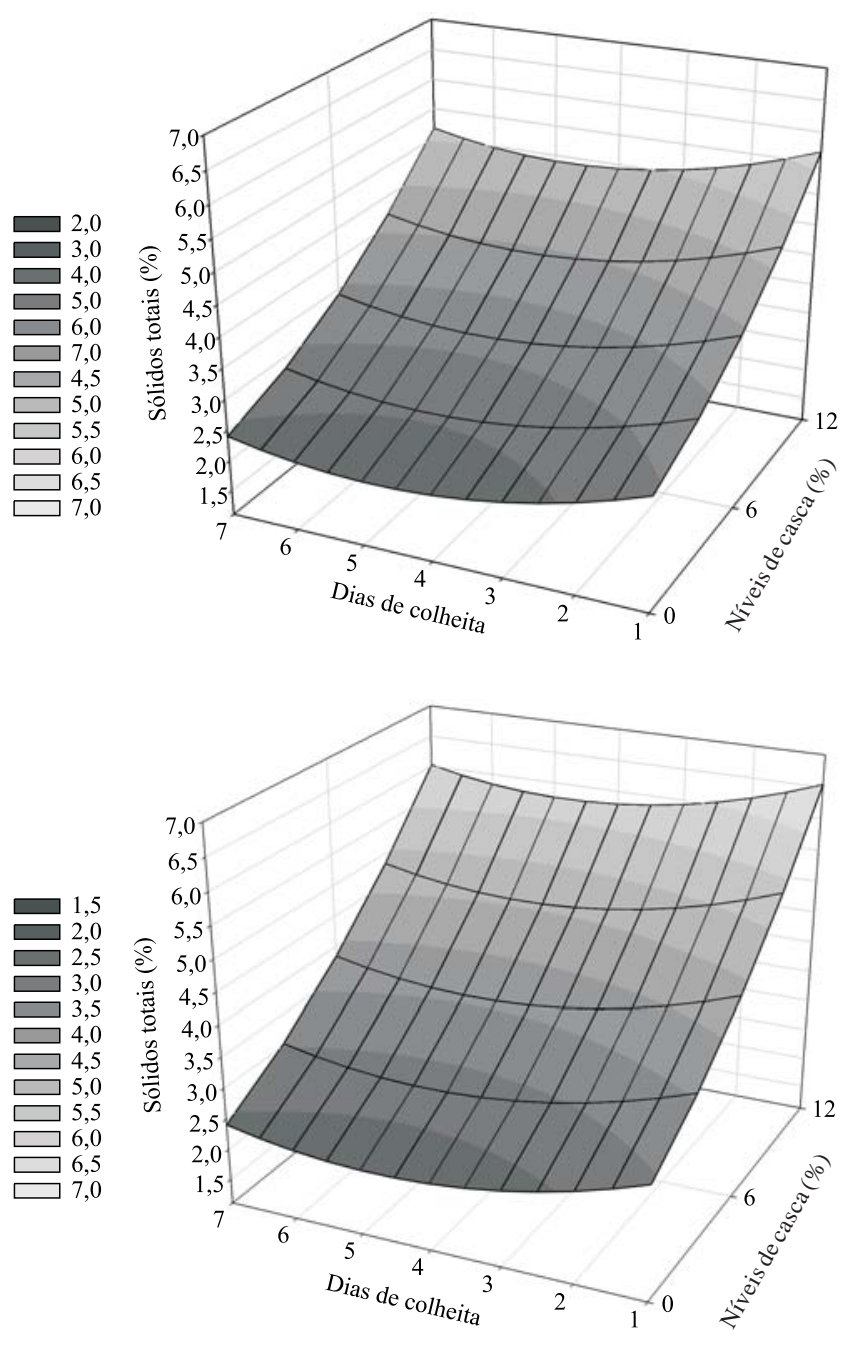

$\hat{\mathrm{Y}}=3,39755+0,104273 * \mathrm{CA}+0,010411 * \mathrm{CA}^{2}+0,071489 * \mathrm{CA} \mathrm{PR}-0,520302 * \mathrm{D}+$ $0,054173 * \mathrm{D}^{2} ; \mathrm{R}^{2}=0,8742$

* Significativo a $5 \%$ de probabilidade pelo teste "t"

Figura 2 - Teores de sólidos totais (\%) do efluente de silagens de capim-elefante com casca de café inteira e moída. 
13\% de MS e diferentes compactações, mas o comportamento foi inverso, e os maiores valores também foram encontrados no quinto dia. Bernardino et al. (2005) não encontraram efeito dos dias de colheita para a concentração de sólidos totais do efluente de silagem de capim-elefante sem casca de café, com valor médio observado de 25.466,5 mG/L.

O valor médio de sólidos totais do efluente foi de 38.630,0 mG/L e, portanto, está na faixa descrita na literatura, de 1.000 a 110.000 mG/L. A inclusão de casca de café promoveu aumento no teor de sólidos totais do efluente, portanto a presença do aditivo pode aumentar as perdas, apesar de reduzir a produção de efluente, e não é a única forma de perdas no processo de ensilagem.

Para o nitrogênio total (NT) (mG/L) (Figura 3), observou-se efeito quadrático dos dias de colheita e dos níveis de casca de café, assim como interação entre doses de casca e processamento $(\mathrm{P}<0,05)$. Os valores máximos estimados foram encontrados no quinto $(4,8)$ dia, quando os teores foram, respectivamente, 749, 2; 858,1 e 1.124, 8 mG/L para 0; 6 e $12 \%$ de casca de café inteira e de 749,2; 878,4 e 1164,4 mG/L para 0; 6 e 12\% de casca de café moída. Bernardino et al. (2005) encontraram efeito linear positivo dos dias de colheita para a concentração de nitrogênio total do efluente de silagem de capim-elefante, com valor estimado de 790,3 mG/L para o primeiro dia e acréscimo de 6,035 mG/L de nitrogênio total por dia de colheita. Loures et al. (2003), trabalhando com silagem de capim-elefante com 13\% de MS, também encontraram efeito quadrático dos dias de colheita na concentração de nitrogênio total do efluente e relataram que os teores máximos variaram de 1.177,8 a 1.644,7 mG/L para as compactações estudadas e foram encontrados no quinto dia. Bernardes et al. (2003) observaram aumento nos teores de nitrogênio total do efluente de silagens de capimmarandu com a inclusão de polpa cítrica peletizada e verificaram os maiores valores de nitrogênio total no quarto dia. Para silagens de gramíneas de clima temperado, Haigh (1999) relatou que os valores de nitrogênio total do efluente se encontram entre 1.000 e $5.000 \mathrm{mG} / \mathrm{L}$.

Houve efeito do processamento e efeito quadrático dos dias de colheita $(\mathrm{P}<0,05)$ (Figura 4 ) sobre os teores de cálcio do efluente das silagens, mas não houve efeito dos níveis de casca de café. Os teores mínimos de 3,6 mG/L para a casca inteira e de $3,5 \mathrm{mG} / \mathrm{L}$ para a moída ocorreram no quinto (5,2 e 4,6, respectivamente) dia e foram muito baixos. Outros autores, no entanto, não encontraram cálcio no efluente das silagens de capim-elefante (Loures et al., 2003; Bernardino et al., 2005) e relacionaram esse resultado à imobilidade desse mineral no tecido vegetal.
Além disso, o processamento da casca também diminui os teores de cálcio no efluente (Figura 4).

Os dias de colheita e a inclusão de casca de café tiveram efeito quadrático $(\mathrm{P}<0,05)$ nos teores de magnésio no efluente (Figura 4), cujos valores máximos foram de 304,2; 375,9 e 447,8 mG/L, respectivamente, para as silagens com 0; 6 e $12 \%$ de casca, no quarto $(3,7)$ dia. Por outro lado, Bernardino et al. (2005), trabalhando com silagem de capim-elefante, encontraram efeito linear dos dias de colheita, com teor de 183,7 mG/L no primeiro dia e decréscimo de 1,079 mG/L por dia. Loures et al. (2003) não detectaram efeito dos dias de colheita do efluente sobre os teores de magnésio, cujo valor médio foi de $0,3997 \%$ da MS em silagem de capim-elefante com diferentes compactações.
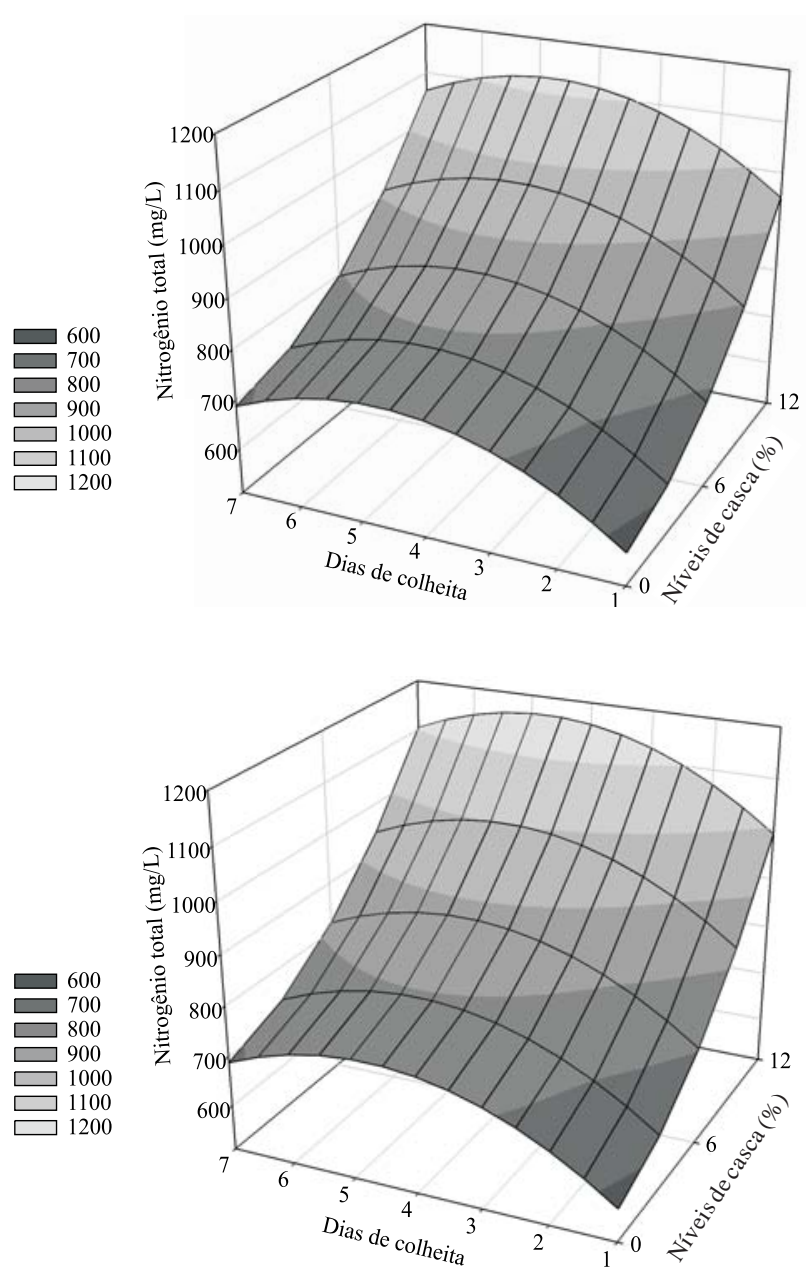
$\hat{Y}=471,162+5,08972 * C A+2,17666 * C^{2}+3,39565 * C A P R+116,609 *$
$D-12,2274 * D^{2} ; R^{2}=0,7878$

* Significativo a $5 \%$ de probabilidade pelo teste t.

Figura 3 - Teores de nitrogênio total (mG/L) do efluente de silagens de capim-elefante com casca de café inteira ou moída. 

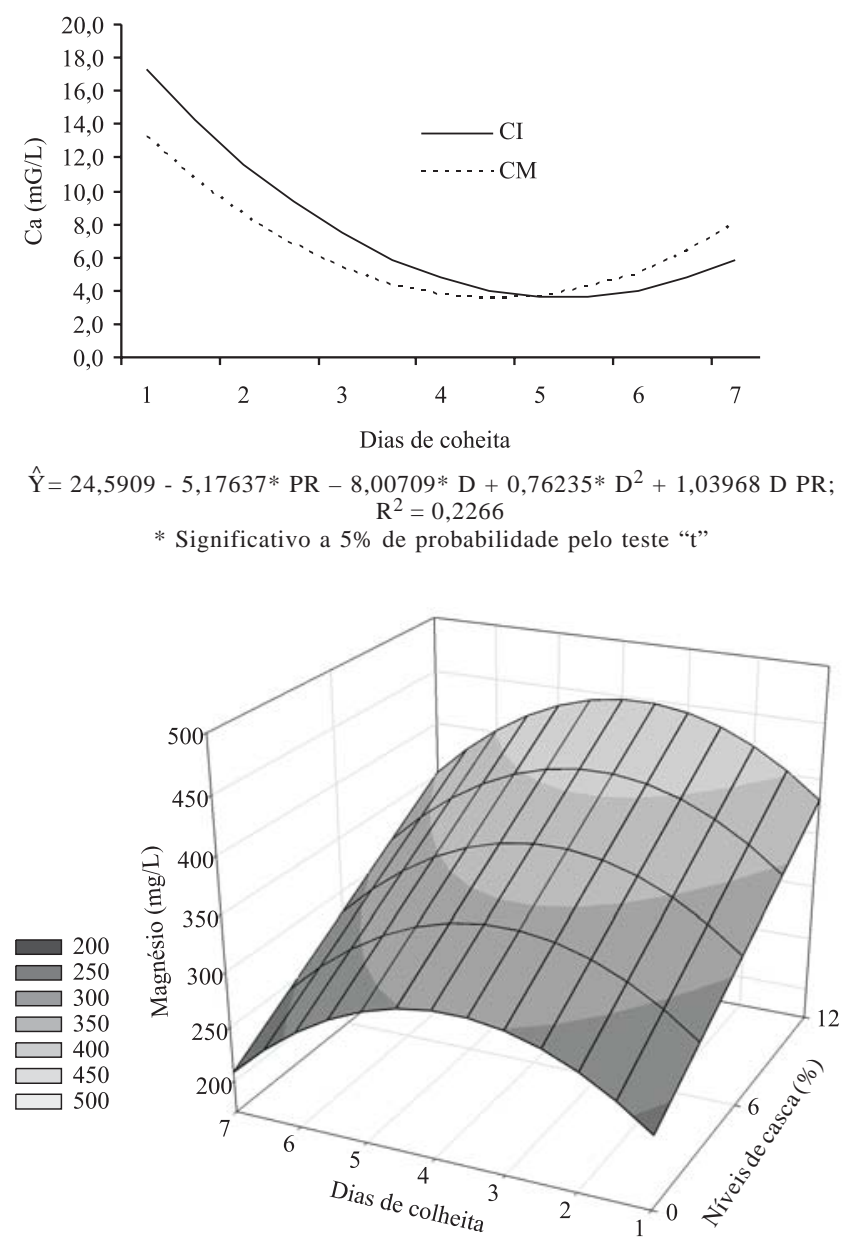

$\hat{\mathrm{Y}}=179,285+11,9643 * \mathrm{CA}+66,9282 * \mathrm{D}-8,96498 * \mathrm{D}^{2} ; \mathrm{R}^{2}=0,6761$ * Significativo a $5 \%$ de probabilidade pelo teste " $\mathrm{t}$ "

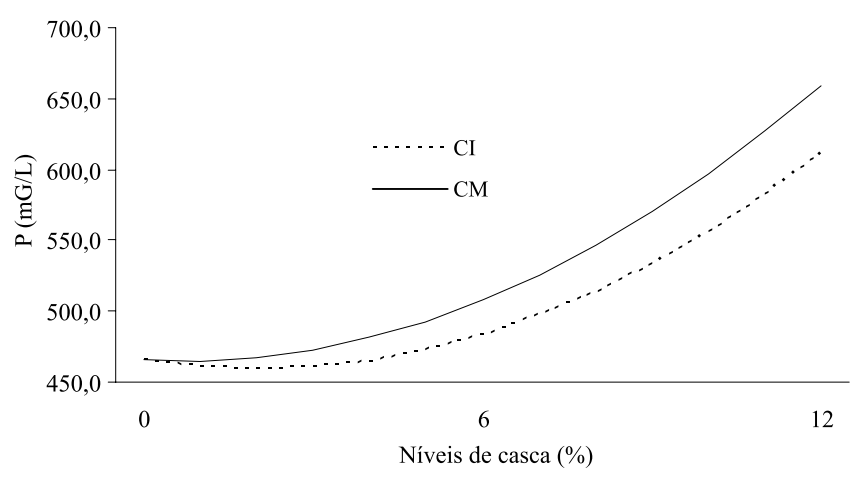

$\hat{\mathrm{Y}}=465,214-6,12123 * \mathrm{CA}+1,52257 * \mathrm{CA}^{2}+4,04424 \mathrm{CA} \mathrm{PR} ; \mathrm{R}^{2}=0,5071$ * Significativo a $5 \%$ de probabilidade pelo teste " $\mathrm{t}$ "

Figura 4 - Teores de cálcio, magnésio e fósforo (mG/L) do efluente da silagem de capim-elefante contendo casca de café inteira (CI) e moída (CM).

Os valores de potássio, média de 6285,71 mG/L, não foram influenciados pelos níveis de casca de café, pelo processamento ou pelos dias de colheita do efluente. Bernardino et al. (2005) também detectaram o mesmo comportamento desse mineral no efluente de silagem de capim-elefante e relataram valor médio mais baixo, de 4323,6 mG/L. Diferentemente, Loures et al. (2003) verificaram que os teores máximos desse elemento em todos os níveis de compactação estudados foram observados no quarto dia de colheita de efluente.

Os dias de colheita não influenciaram os teores de fósforo do efluente das silagens $(\mathrm{P}>0,05)$, que foram afetados $(\mathrm{P}<0,05)$ apenas pelos níveis de casca de café e pela interação níveis de casca de café $\times$ processamento (Figura 4). O efluente das silagens com casca moída apresentou teores mais elevados de fósforo, fato que pode ser explicado pela menor produção de efluente nesta silagem. De forma semelhante, Bernardino et al. (2005) verificaram que os teores de fósforo do efluente da silagem de capimelefante não se alteraram entre os dias de colheita, resultando em valor médio de 429,7 mG/L. Entretanto, esses resultados divergem dos encontrados por Loures et al. (2003), que observaram aumento dos teores de fósforo no efluente com o passar dos dias em silagens de capim-elefante.

Os dias de colheita, os níveis de casca, o processamento e a interação entre nível de casca e processamento $(P<0,05)$ influenciaram a demanda química de oxigênio (Figura 5). No quarto dia $(4,04)$, ocorreram os valores máximos estimados de demanda química de oxigênio, de 34178,6; 46523,2 e 65907,0 $\mathrm{mG} \mathrm{O}_{2} / \mathrm{L}$ para os níveis 0, 6 e $12 \%$ de casca inteira e de 34178,6; 51669,3 e de 76199,2 $\mathrm{mG} \mathrm{O}_{2} / \mathrm{L}$ para as doses de 0 , 6 e $12 \%$ de casca moída, respectivamente. Hameleres et al. (1999) também encontraram aumento na demanda química de oxigênio com a adição de polpa de beterraba à silagem de milho, com valores de $84 ; 114$; 112; 141 e 161 g O$_{2} / \mathrm{L}$, respectivamente, para $0 ; 2 ; 7 ; 13$ e $18 \%$ de aditivo. Contrastando com esses resultados, Bernardino et al. (2005) e Loures et al. (2003) não notaram influência do dia de colheita na demanda química de oxigênio de silagens de capim-elefante sem aditivo (38334,0 e 31138,2 $\mathrm{mG} \mathrm{O}_{2} / \mathrm{L}$, respectivamente).

Os dias de colheita, os níveis de inclusão, o processamento e a interação entre nível de casca e processamento influenciaram $(\mathrm{P}<0,05)$ a demanda bioquímica de oxigênio (Figura 5). No sexto $(5,7)$ dia, foram verificados os valores máximos estimados de demanda bioquímica de oxigênio, de 14678,0; 18427,4 e 26566,2 mG O $_{2} / \mathrm{L}$ para os níveis de 0, 6 e $12 \%$ de casca inteira e de $14.678,0 ; 20.654,3$ e de $31.020,0 \mathrm{mg}$ $\mathrm{O}_{2} / \mathrm{L}$ para os níveis de 0,6 e $12 \%$ de casca moída, respectivamente. Bernardino et al. (2005) e Loures et al. (2003) não notaram influência dos dias de colheita na demanda bioquímica de oxigênio. Bernardes et al. (2003), no entanto, encontraram para silagem de capim-marandu diferença significativa na demanda bioquímica de oxigênio entre os dias de colheita, com valores maiores no quarto dia. 
Também verificaram aumento na demanda bioquímica de oxigênio do efluente da silagem de capim-marandu com a inclusão de polpa cítrica peletizada, com valores máximos de 13.900; 22.000 e $48.700 \mathrm{mG} \mathrm{O}_{2} / \mathrm{L}$ para silagens com 0 , 5 e $10 \%$ de casca, respectivamente. Woolford (1978) relatou que a demanda bioquímica do efluente de silagem é de $90.000 \mathrm{mg} \mathrm{O}_{2} / \mathrm{L}$, enquanto a demanda bioquímica de oxigênio do esgoto doméstico é de apenas $500 \mathrm{mG} \mathrm{O}_{2} / \mathrm{L}$.
Os valores de demanda química e bioquímica de oxigênio neste trabalho e na literatura nacional foram bem inferiores aos encontrados na literatura internacional, mas ainda são bastante elevados, pois, segundo Copam (1986) e Feam (1998), a legislação brasileira estipula os valores máximos de demandas bioquímica e química de oxigênio de 60 e $90 \mathrm{mG} \mathrm{O}_{2} / \mathrm{L}$, respectivamente, para os esgotos e dejetos lançados em cursos d’água e rios.
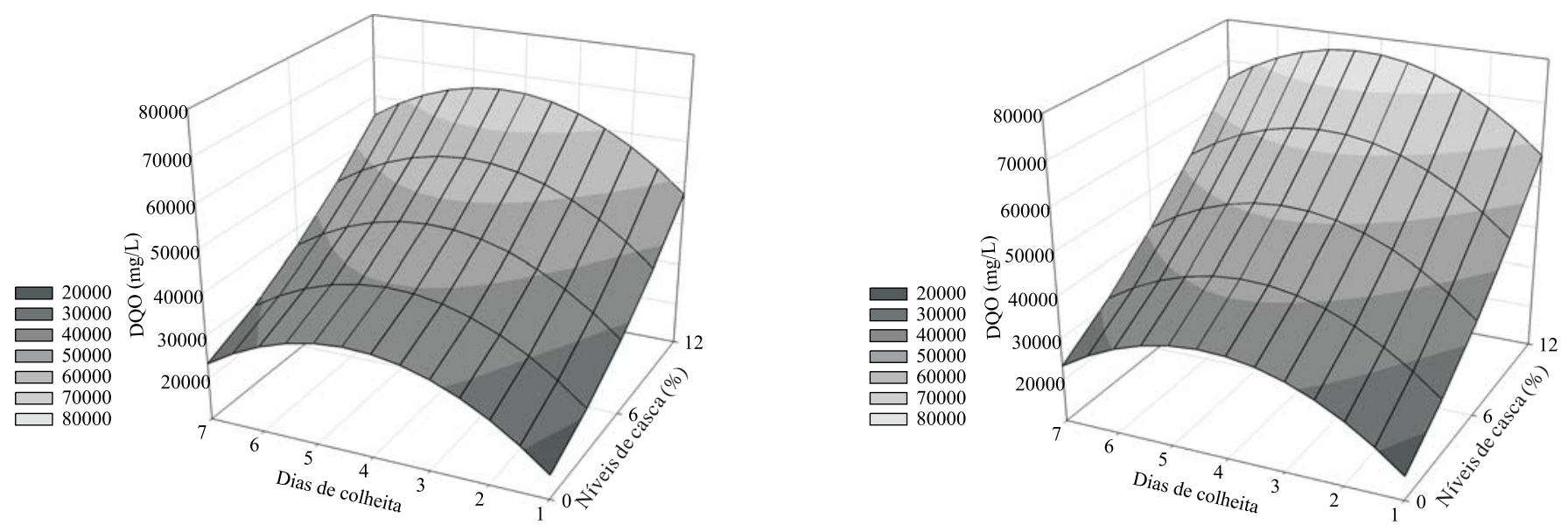

$\hat{Y}=3011,53+1470,84 * C A+97,7661 * C^{2}+857,685 C A P R+14245,8 D-1616,99 D^{2} ; R^{2}=0,8186$ * Significativo a $5 \%$ de probabilidade pelo teste $\mathrm{t}$
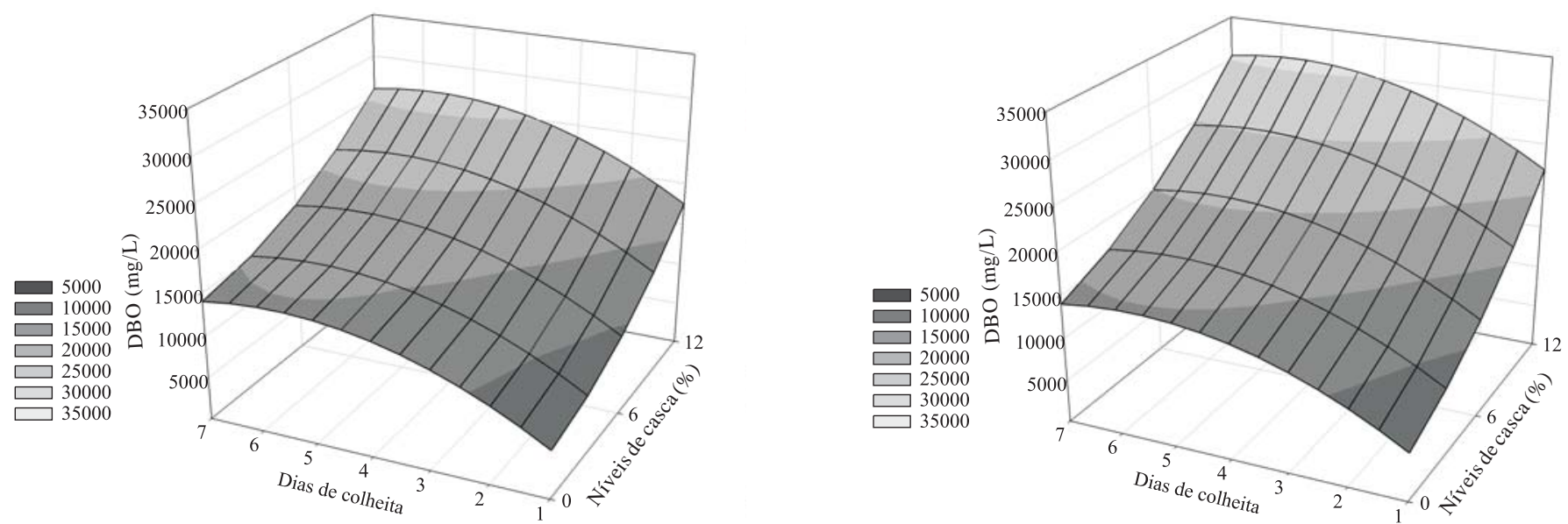

$\hat{Y}=1372,38+259,129 * C A+60,9632 * C^{2}+371,151 C A P R+4645,48 D-405,477 D^{2} ; R^{2}=0,7903$ * Significativo a $5 \%$ de probabilidade pelo teste $\mathrm{t}$.

Figura 5 - Demandas química de oxigênio (DQO) e demandas bioquímicas de oxigênio (DBO) do efluente de silagens de capim-elefante com casca inteira (CI) e moída (CM).

\section{Conclusões}

A casca de café é eficiente em reduzir a produção de efluente e quando incluída nos níveis de 18\% e 24\%, moída e inteira, torna a produção de efluente da silagem quase nula. A casca de café moída é mais efetiva em reduzir a produção de efluente que a casca inteira, portanto, é recomendável seu processamento para inclusão em níveis mais baixos, 6 e $12 \%$, enquanto em níveis iguais ou superiores a 18\%, a moagem torna-se dispensável. A composição do efluente é influenciada pelos níveis de casca de café, pelo processamento e pelos dias de colheita do efluente. 


\section{Referências}

BERNARDES, T.F.; REIS, R.A.; AMARAL, R.C. et al. Produção e composição do efluente das silagens de capim-marandu (Brachiaria brizantha cv. Marandu) submetidas à adição de polpa cítrica peletizada. In: REUNIÃO ANUAL DA SOCIEDADE BRASILEIRA DE ZOOTECNIA, 40., 2003, Santa Maria. Anais... Santa Maria: Sociedade Brasileira de Zootecnia, 2003. (CD-ROM).

BERNARDINO, F.S.; GARCIA, R.; ROCHA, F.C. et al. Produção e características do efluente e composição bromatológica da silagem de capim-elefante contendo diferentes níveis de casca de café. Revista Brasileira de Zootecnia, v.34, n.6, p.2185-2191, 2005 (supl.).

COPAM. Legislação ambiental. 3.ed. Belo Horizonte: Imprensa Oficial, 1986. 183p.

FUNDAÇÃO ESTADUAL DO MEIO AMBIENTE - FEAM. Licenciamento ambiental: coletânea de legislação. In:

Manual de saneamento e proteção ambiental para municípios. Belo Horizonte: 1998. 332p.

HAIGH, P.M. Effluent production form grass silages treated with additives and made in large-scale bunker silos. Grass and Forage Science, v.54, p.208-218, 1999.

HAMELERES, A.; LEACH, K.A.; OFFER, N.W. et al. The effects of incorporating sugar beet pulp with forage maize at ensiling on silage fermentation and effluent output using drum silos. Grass and Forage Science, v.54, p.322-335, 1999.
JONES, R.; JONES, D.I.H. The effect of in-silo effluent absorbent on effluent production and silage quality. Journal of Agricultural Engineering Research, v.64, p.173-186, 1996.

LOURES, D.R.S.; GARCIA, R.; PEREIRA, O.G. et al. Características do efluente e composição químico-bromatológica da silagem de capim-elefante sob diferentes níveis de compactação. Revista Brasileira de Zootecnia, v.32, n.6, p.1851-1858, 2003 (supl.2).

NUSSIO, L.G.; PAZIANI, S.F.; NUSSIO, C.M.B. Ensilagem de capins tropicais. In: REUNIÃO ANUAL DA SOCIEDADE BRASILEIRA DE ZOOTECNIA, 39., 2002, Recife. Anais... Recife: Sociedade Brasileira de Zootenia, 2002. p.60-99.

PEREIRA, O.G.; BERNARDINO, F.S. Controle de efluentes na produção de silagem. In: SIMPÓSIO SOBRE MANEJO ESTRATÉGICO DA PASTAGEM, 2., 2004, Viçosa, MG. Anais... Viçosa, MG: Universidade Federal de Viçosa, 2004. p.509-545.

SILVA, M.O.S.A. Análises físico-químicas para controle de estação de tratamento de esgotos. São Paulo: CETESB, 1977. 266p.

SILVA, D.J.; QUEIROZ, A.C. Análise de alimentos: métodos químicos e biológicos. Viçosa, MG: UFV, Imprensa Universitária, 2002. 235p.

UNIVERSIDADE FEDERAL DE VIÇOSA - UFV. SAEG - Sistema de análises estatísticas e genéticas. Versão 7.1. Viçosa, MG: 1997. 150p. (Manual do usuário).

WOOLFORD, M.K. The problem of silage effluent. Herbage Abstracts, v.48, p.397-403, 1978. 